\title{
Julio Victor Iribarne, November 11, 1916-November 15, 2012
}

$\mathrm{J}$ ulio Iribarne, known in our field for developing the theory of ion evaporation, died recently at the age of 96. Ion evaporation is one of the two proposed explanations for the process of ion emission from charged droplets at atmospheric pressure. Originally published in two papers in 1976 and 1979, the theory was largely unrecognized in the mass spectrometry community until the explosion of interest in electrospray ionization in the late 1980s. Julio developed the theory to explain observations arising from my Ph.D. work in his lab in the Department of Physics at the University of Toronto. This work was directed at understanding what happens to the charges on cloud droplets when they evaporate, and it built on earlier work by Chapman and others who had noted that small, high mobility charge carriers were created. Our experiments using ion mobility and mass spectrometry identified the small ions that remained in the air when droplets evaporated. Rather than accept the previous explanations that these were simply residues of evaporated droplets, Julio proposed that ion emission from a charged droplet could be an activated process that competed with Rayleigh instability in certain regimes, and he developed a relatively simple but rigorous theory to support this idea. Julio, originally trained as a chemist, also recognized the potential analytical applications of this technique, and initiated some experiments with some small biomolecules to prove that these too could be emitted from charged droplets. Unfortunately, he did not consider trying to apply this method to proteins or larger biomolecules, and so the method did not attract much attention as an analytical technique, even when it was coupled to liquid chromatography.

It was John Fenn who recognized the similarities of ion evaporation and electrospray methods, and he brought Julio's work and the theory to the attention of the mass spectrometry community. Offered as a competing explanation to the charge residue theory of Malcolm Dole, the two theories have been debated and discussed for many years without complete resolution, but with the recognition that the truth is probably somewhere between.

Julio was born in Argentina in 1916, and after obtaining his doctorate in chemistry at the University of Buenos Aires in 1942, he held a variety of research and teaching positions at the university. From 1957 to 1966 he was head of the Institute of Atmospheric Physics at the National Meteorological Service in Argentina. There, he oversaw some of the earliest cloud-seeding experiments. In 1966, his dissatisfac-

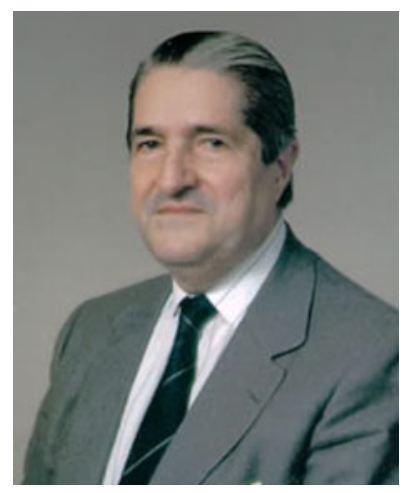

tion with the political situation in Argentina led him to emigrate to Toronto, where he assumed a position in the atmospheric physics group in the physics department, coauthoring two textbooks: Atmospheric Thermodynamics in 1973 and Atmospheric Physics in 1980. His interest in microphysical processes in clouds, and cloud electrification, led to a number of challenging experiments in droplet/ droplet and droplet/ice collisions to measure and model the shearing processes that produce charge separation and electrified droplets. That theme led to the project on droplet evaporation, a project that he suggested to me and that led to the theory of ion evaporation.

After formal retirement in 1982, Julio continued research in a completely different area. Together with his wife Agripina, a chemical engineer, he studied the chemistry of residues from combustion of coal in fluidized beds, continuing even with a lab in his home until the age of 87 and publishing some 22 papers in this field.

Along with his varied scientific contributions, Julio was a gifted amateur violinist throughout his life, eventually finding time to study chamber music seriously at the university after his retirement. Widely read in three languages, he was particularly fond of French literature, poetry, and culture, as well as good food and un buen venito. A modest man and a gentleman in the true sense of the word, his collaborative approach to supervising the work of graduate students was fondly recalled at his memorial.

Bruce Thomson $A B$ SCIEX

Concord, Ontario L4K $4 \mathrm{~V} 8$

Canada 